\title{
Study on Burr Formation at the Top Edge in Rectangular Groove Cutting
}

\author{
Wen Jun Deng, Zi Chun Xie, Ping Lin, and Tong Kui Xu \\ School of Mechanical and Automotive Engineering, South China University of Technology, Guangzhou 510641, China \\ Correspondence should be addressed to Wen Jun Deng, dengwj@scut.edu.cn
}

Received 15 September 2011; Revised 30 December 2011; Accepted 4 January 2012

Academic Editor: Ming-Xing Zhang

Copyright () 2012 Wen Jun Deng et al. This is an open access article distributed under the Creative Commons Attribution License, which permits unrestricted use, distribution, and reproduction in any medium, provided the original work is properly cited.

Previous research on burr formation in machining operations has usually been limited to the study of the rollover burr in the cutting direction. In this paper, a 3D finite element model to simulate rectangular groove cutting operation has been developed using commercial finite element software, employing experimentally determined mechanical properties at elevated strain rates and temperatures. The plastic deformation behavior and three-dimensional burr formation during rectangular groove cutting is investigated. The simulated burr profile and cutting force prove that the developed model can capture the thermo-mechanical mechanisms in rectangular groove cutting and can simulate burr development with considerable accuracy. The study concentrates on the influence of cutting parameters on burr formation which are also conducted. The results show that the feed rate and rake angle are the cutting parameters which have a major influence on burr size in the groove cutting operation. And the effect of cutting velocity and minor clearance angle in the traditional range on burr size are quite limited.

\section{Introduction}

Burrs are one of the most serious obstacles to precision manufacturing and manufacturing process automation. Burrs are formed in various machining process as a result of plastic deformation due to plasticity during mechanical manufacturing process and have been defined as undesirable projections of material beyond the edge of a workpiece. Recently, the trends of machined parts move towards more miniaturization and precision, burrs cause many problems during inspection, assembly, and manufacturing automation of precision components.

Burrs have to be removed by a deburring process for functional and aesthetic reasons after the part is machined. However, deburring processes are usually not very precise and may decrease the precision of the machined parts, damage surface finish, and produce residual stresses in the component. Moreover, adding a deburring process means extra cost, extra manufacturing time, and an extra machining station. Gillespie [1] found that on precision components, deburring operations can account for as much as $30 \%$ of the total part cost. Since burr generation in cutting cannot be avoided completely, it is very important to find a solution for minimizing the burr formation or more effective deburring method. It is also necessary to understand the burr formation mechanism and the relationship between the parameters involved in the machining operation and burr formation. A thorough analysis of mechanism of burr formation may improve the quality of the machined parts greatly and thus be critical.

A great deal of research has focused on the development of more efficient deburring techniques to reduce the cost of deburring. In contrast, only a few studies have been carried out on the mechanisms of burr formation and the influence of cutting parameters to assist in the reduction of burrs and the production of burr-free components. Gillespie [2] identified the machining burrs into four specific types based on the mechanism of their formation: poisson burr, rollover burr, tear burr, and cutoff burr. Iwata et al. [3] discussed the dependence of burr formation on the stress field in machining. In order to clarify the effects of tool and workpiece geometry on burr formation, it is desirable to simulate, as closely as possible, these types of stress fields along the workpiece edge for various tool and workpiece geometry combinations. Ko and Dornfeld [4] proposed a quantitative model of burr formation for ductile materials in orthogonal machining. Later, Ko and Dornfeld [5] proposed a new model that caters for both ductile and brittle 
materials in orthogonal cutting. Chern [6] extended Ko and Dornfeld's model of burr formation with more realistic machining operations and cutting conditions. According to his observation, four different types of burrs-knifeedge, curl, wave, and secondary burr-were formed with variations in depth of cut and in-plane exit angle. Guo and Dornfeld [7] developed a 3D finite element model for drilling with two sets of backup materials to investigate mechanisms of drilling burr minimization and predict cutting forces. Park and Dornfeld [8] developed the finite element model of the burr formation in 2D orthogonal cutting with a plane strain assumption and investigated the influences of various process parameters. The four stages of burr formation, that is, initiation, initial development, pivoting point, and final development stages, are investigated based on the stress and strain contours with the progressive change of geometry at the edge of the workpiece. In addition, the characteristics of thick and thin burrs are clarified along with the negative deformation zone formed in front of the tool edge in the final development stage. Park and Dornfeld [9] also conducted finite element simulation to investigate mechanisms of burr minimization by backup material and concluded that the burr can be effectively minimized by this way. Min et al. [10] also present a general finite element model for burr formation in metals. And these simulation tools show excellent correlation with experimental results. The advantage of the simulation approach is that a wide range of parameters can be evaluated relatively quickly. Saunders and Mauch [11] also developed a finite element model of burr formation to address the limitations of classical models of burr formation in drilling. Toropov and Ko [12] proposed a model of the burr formation mechanism when burrs are formed in the feed direction during turning operation. Two cases have been considered in this study: continuous burr development, when the burr grows uninterruptedly, and discontinuous development, when the burr being formed is cut off and is renewed with each revolution of the workpiece. The model allows predicting burr height and thickness and is able to simulate burr development. Deng et al. [13] established a coupled thermomechanical model of planestrain orthogonal metal cutting including burr formation is presented using the commercial finite element code. A simulation procedure based on Normalized Cockroft-Latham damage criterion is proposed for the purpose of better understanding the burr formation mechanism and obtaining a quantitative analysis of burrs near the exit of orthogonal cutting. Sartkulvanich et al. [14] focused on the effects of tool geometry and flank wear upon burr formation in face milling of a cast aluminum alloy. $3 \mathrm{D}$ face milling simulations were conducted to investigate more realistic chip flow and burr generation. Comparisons were made for burrs produced from 3D simulations with a sharp tool, 3D simulations with a worn tool, and face milling experiments. Some recommendations for cutting tool design were made to reduce burr formation in face milling.

Up to now, little research on burr at top side is reported in the literature. The experimental work and practical theoretical models including finite element analysis are also scarce. The advantages of using finite element method to study machining can be seen from the following aspects:

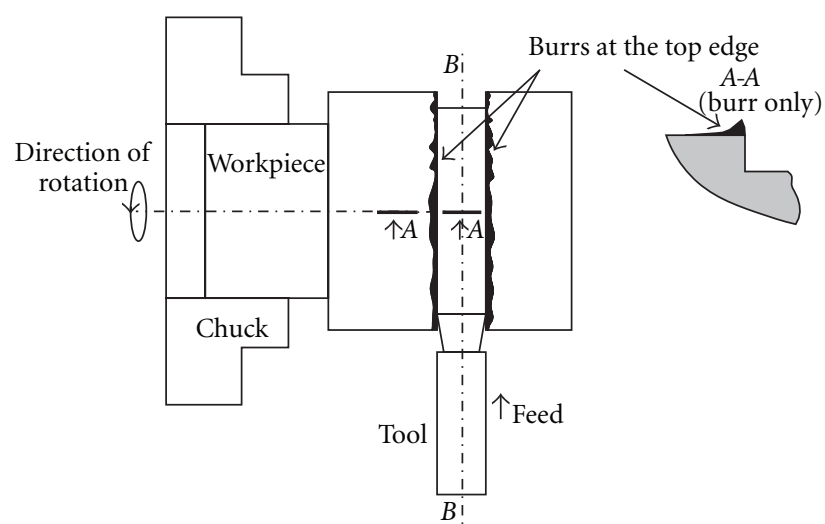

FIGURE 1: Burrs produced in the rectangular groove cutting operation.

Material properties can be handled as functions of strain, strain rate and temperature. The interaction between chip and tool can be modeled as the sticking and sliding frictional behavior. And nonlinear geometric boundaries such as the free surface of the chip can be represented and used.

Some researchers adopted 2D FEM simulation programs to provide some insight to the fundamental understanding of burr formation $[10,13,15,16]$. However, most of these models are two-dimensional, which can only be used for the analysis of roll burr formation in orthogonal cutting because of geometrical simplicity and is not suitable for predicting burr at top edge for its geometrical complicity. To date, there is few 3D finite element model has not been reported in the literature for analyzing burr formation at the top edge. In addition, in most of the finite element models developed so far, few commercial finite element codes have been employed. In order to improve the fundamental understanding of burr formation and process optimization for producing favorable surface integrity, theoretical modeling of burr formation has economic as well as scientific importance.

Since burrs are the cause of misfits in precision assembly, in this research, a general practical 3D FEA model has been developed to analyze the burr formation at top edge during groove cutting. A study concentrates on mechanism of burr formation in groove cutting and the influence of the main cutting parameters, namely, feed, rake angle, and cutting velocity on burr formation are presented in this paper.

\section{Finite Element Modeling of Groove Cutting}

The sketch of rectangular groove cutting is shown in Figure 1 with the burr formed at the top edge. A rectangular groove is formed by turning using high speed steel cutting tools. This study mainly aims at the burr formation at top edge and the relationship between the parameters involved in the rectangular groove cutting operation. A 3D thermomechanically coupled finite element model of groove cutting process has been developed by using commercial finite element code (Deform-3D) as shown in Figure 2. The modeling approach is based on updated Lagrange formulation for large plastic 

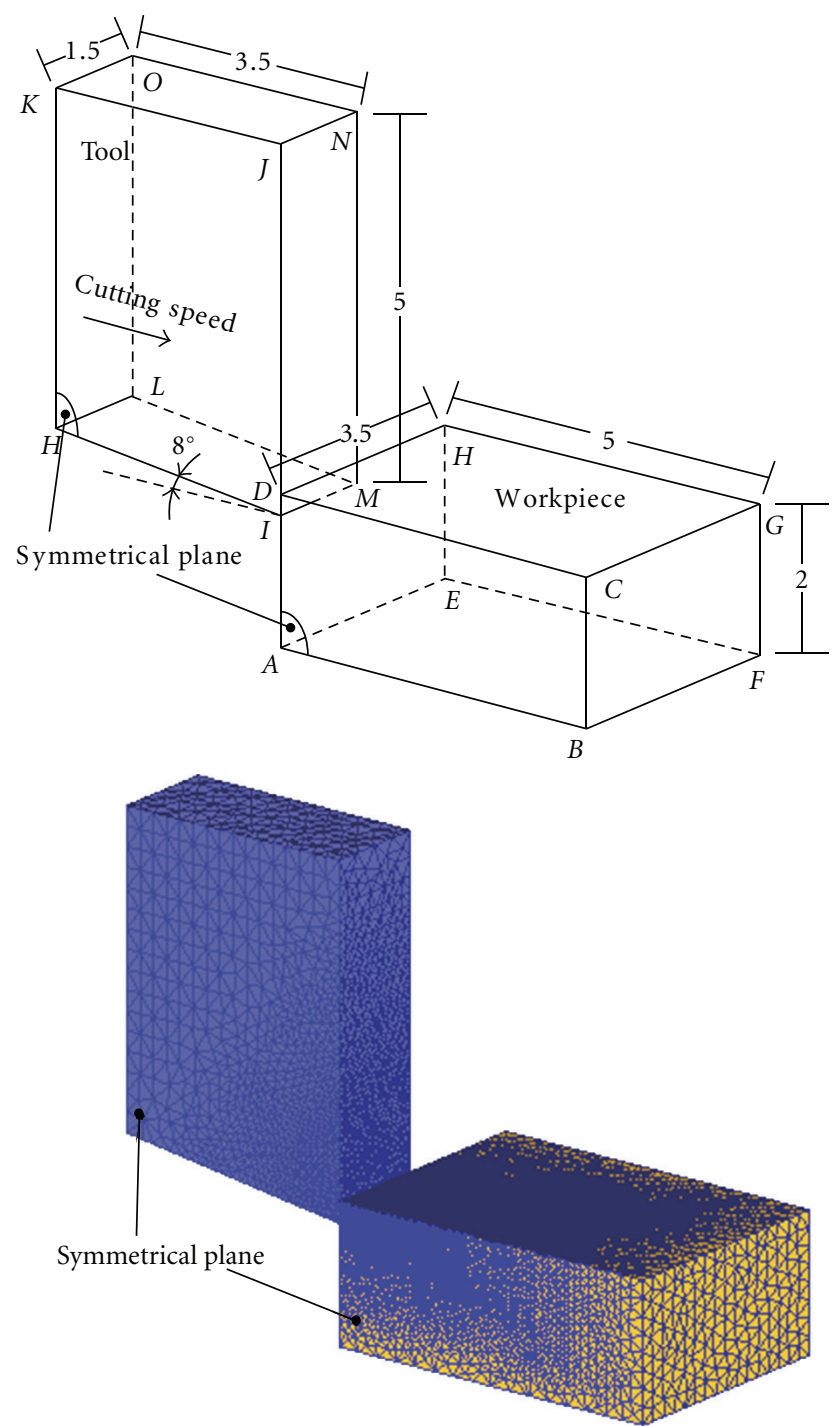

Figure 2: The geometry and mesh models of rectangular groove cutting.

deformation analysis to simulate the chip formation and burr formation. In the finite element simulation, the concepts of symmetry and antisymmetry are often useful and can reduce the size of the model (the total number of nodes and elements), which can reduce the analysis run time as well as the demands on computer resources. In Figure 1, for both the geometry and boundary conditions of the finite element model is identical on either side of a dividing plane B-B, the model then can be simplified to 180 degree segment due to symmetry. For the radius of bar-shaped workpieces used in experimental groove cutting is larger and the modeled section in the finite element simulation study is very small, the geometric shape of the modeled segmental material can be approximately taken as a cuboid. The cuboid has length $5 \mathrm{~mm}$, width $3.5 \mathrm{~mm}$, and height $2 \mathrm{~mm}$. The workpiece model includes more than 200,000 elements. A very fine mesh density is defined at the cutting zone to obtain fine process output distributions.

The workpiece material used for the plane-strain orthogonal metal cutting simulation is Al6061-T6. The workpiece

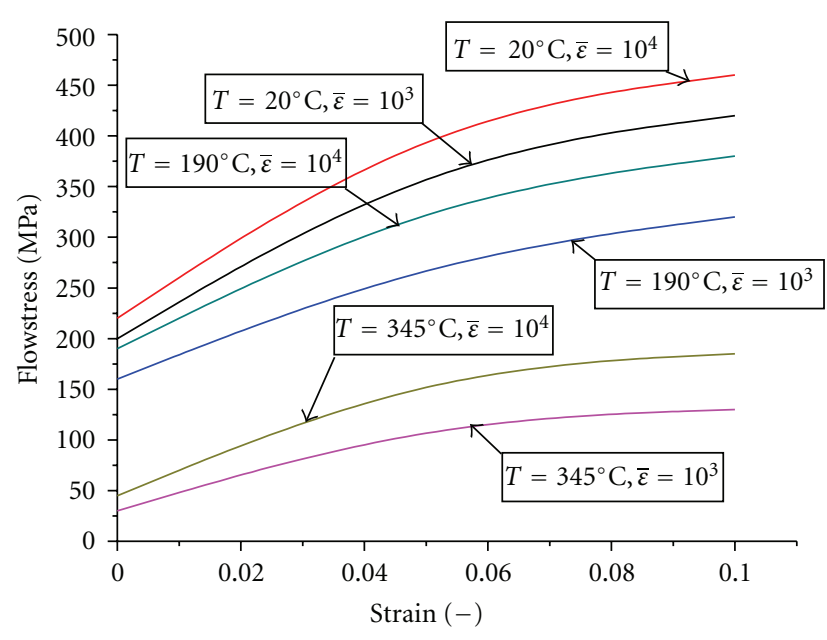

Figure 3: Flow stress for Al6061-T6.

is a deformable body with rigid-plastic material data, which depends on strain, strain rate, and temperature. Its flow curve is represented by several tabulated data, which depends on strain, strain rate, and temperature. These data represent the material flow curve at different strain rates and temperatures, while strain changes between 0 and 0.1 . A sample flow curve for Al6061 at strain rate $10^{3}$ and $10^{4}$ can be seen in Figure 3. In the cutting process, the deformation at the cutting zone takes place at elevated temperatures and strain rates. For example, in the simulations performed, the temperature reaches above $300^{\circ} \mathrm{C}$ and the strain rates are in the order of $10^{5} \mathrm{~s}^{-1}$. Therefore, the flow stresses at other strain rate state and temperature state are obtained by extrapolation.

The surface $A B C D$ and $H I J K$ is the symmetry surfaces for workpiece and cutting tool, respectively. The surface $A B F E$, $B C G F$, and FGHE of the workpiece are fixed in all directions. The cutting tool is modeled as a rigid body which moves at the specified cutting speed by using 125,000 elements. A very fine mesh density is defined at the tip of the tool and at the contact zone to obtain fine temperature distributions. The minimum element size for the workpiece and tool mesh was set to 0.025 and $0.009 \mathrm{~mm}$, respectively.

The heat sources responsible for large temperature rise during groove cutting include:

(a) heat generation due to plastic deformation of the workpiece (mechanical energy) in the primary and secondary deformation zones;

(b) heat generated at the tool-chip and tool-workpiece interface due to friction.

For the heat transfer calculation, the following assumptions were made:

(a) the main sources of heating in metal cutting process are the plastic work and the friction at the tool/workpiece interface. In this study, $90 \%$ of the plastic deformation and $100 \%$ of the frictional work is assumed to be converted into heat; 
(b) the tool-chip contact is thermally perfect, namely, a very large value for the interface heat transfer coefficient is used;

(c) the surface $A B F E, B C G F$ of workpiece and surface $H L O K, K J N O$ of tool are away from the cutting zone and remain at the room temperature; other free surfaces on the workpiece, chip, and tool, heat loss due to heat convection was considered;

(d) Heat transfer by radiation is considered insignificant and negligible. Therefore, it is not therefore taken into account.

To simulate the chip formation, an automatic adaptive remeshing procedure is performed very frequently to deal with large deformation without losing accuracy. So that the workpiece mesh is frequently updated and modified, especially at the edge of the cutting tool, to follow the tool progress. This technique makes possible to simulate chip separation from the workpiece without any arbitrary predefinition. In this study, a new mesh is generated when the tool penetrates the workpiece by a critical value, which is assumed to be 30 percent of the smallest element edge length currently existing in the mesh.

In a groove cutting process, due to high stresses, high strain rates, and high temperatures, a high mechanical power is dissipated in the tool-chip interface thus leading to many structural modifications of the contacting pieces. Therefore, no universal contact law exists which can predict friction forces among a wide range of cutting conditions. Friction is difficult to model in metal cutting. Nowadays, it is widely accepted that two distinct contact regions, namely, the sticking region and the sliding region, exist simultaneously along the tool-chip interface $[17,18]$. In the sticking region, a critical friction stress, $\tau_{c}$, is considered to exist, while in the sliding region, a coefficient of friction, $\mu$, is often assumed with regard to the Coulomb friction law. In this model, a classical Coulomb friction law is assumed to model the toolchip and the tool-workpiece contact zones. Friction factor is defined as $m=\tau / k$, where $\tau$ is frictional shear stress and $k$ is the work material shear flow stress. A value of $m=0.5$ is assumed, this one has been determined according to rake face friction factor identification results.

\section{Results and Discussions}

3.1. Burr Formation. An important aspect of metal cutting simulations is the correct modeling of the material separation in front of the tool. Possible approaches are either to predefine a separation line and then separate the nodes on this line when a certain criterion is reached. It is also possible to simulate the metal cutting process without node separation. Instead, the formation of a continuous chip assumed to be due to plastic flow. As the tool advances, all nodes move on the tool surface and the elements may deform strongly. The material that overlaps with the tool can be removed during a remeshing step. Frequent remeshing is necessary so that the amount of material removed remains small. This simple approach has the advantage that it converges more easily and no material separation line is prescribed.

This study uses the deformation technology for burr formation in simulations. The workpiece is remeshed whenever a predefined threshold value of tool penetration occurs. Therefore, a new boundary for the workpiece at the toolchip interface is determined and the workpiece is remeshed according to it forming the chip. The default threshold value of tool penetration is two times the contact tolerance value, which is by default 0.3 times the minimum element edge length. In addition, a penetration check can be selected to be performed at each iteration or the end of increments. Figure 4 shows the deformed mesh and distributions of the effective stress for the model run at $50 \mathrm{~m} / \mathrm{min}$ cutting speed after machining a distance of $0.01 \mathrm{~mm}$ and $1.70 \mathrm{~mm}$, respectively. Successful separation of the material from the workpiece, together with smooth chip flow up the rake face of the tool, is observed. Figures 4(a) and 4(b) show most of the maximum shear stress exhibits a finite region in the shear plane and larger region ahead of tool. The distribution of effective stress shows that the workpiece is most deformed in the chip-tool contact surface.

Figure 5 shows that force components with the time. It can be observed that a steady state is reached very quickly after the initiation of the cutting process. Indeed, the cutting force appears to have attained a constant value at the time of $0.24 \mathrm{~ms}$, indicating the achievement of a steady state. (Both the cutting and the thrust forces have reached the steady state after a tool path of about $2 \mathrm{~mm}$.) When the chip geometry is stable, cutting force reaches a value of $513 \mathrm{~N}$. All experiments were conducted on turning lathe. The cutting tool and conditions used for these experiments were the same as those used in simulations. No coolant was used in the machining. A three-component dynamometer (piezoelectric transducer, Kistler 9257), made by Kistler Co., was clamped on the machine bed to measure the cutting force. The signal generated by the piezoelectric transducer was first amplified by a charge amplifier and then connected to an A/D converter in the PC. The cutting force was determined by the processing using customized measuring force software. The experimental force is also shown in Figure 5. The comparison of the predicted steady-state cutting forces with measured (mostly transient) cutting forces shows that finite element simulation can basically capture the trend observed in the experimental data. The quantitative differences between the predicted and measured data are reasonable. The differences between the experimental and predicted cutting force may be attributed to the following reasons: (i) the extrapolation errors of the material flow stress data at high strain rates and temperatures; (ii) the simplified friction model used for the tool-chip interface; (iii) cutting edge radius.

Figure 6 shows the material flow state during the groove cutting. It can be easily observed the undeformed layer is plastic deformed and pushed forward. Most of the undeformed layer material, that is, material in the shear zone I, move in the direction of the cutting velocity and finally formed the chip. The value of the velocity of material in zone I is approximately equal to the cutting velocity and the direction is also tightly along tool movement. Only a small 

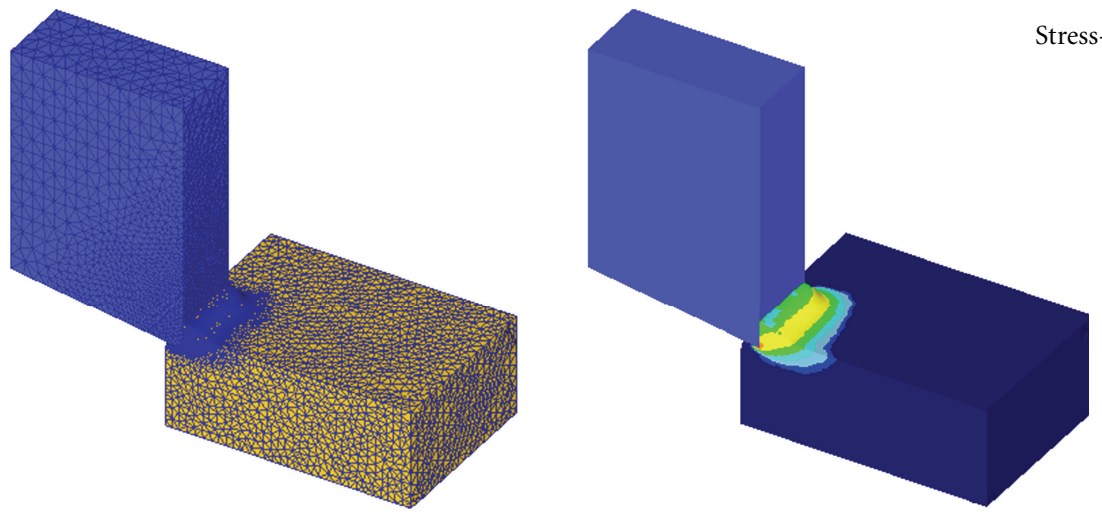

Stress-effective (MPa)

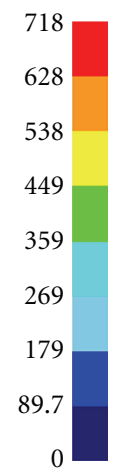

(a)
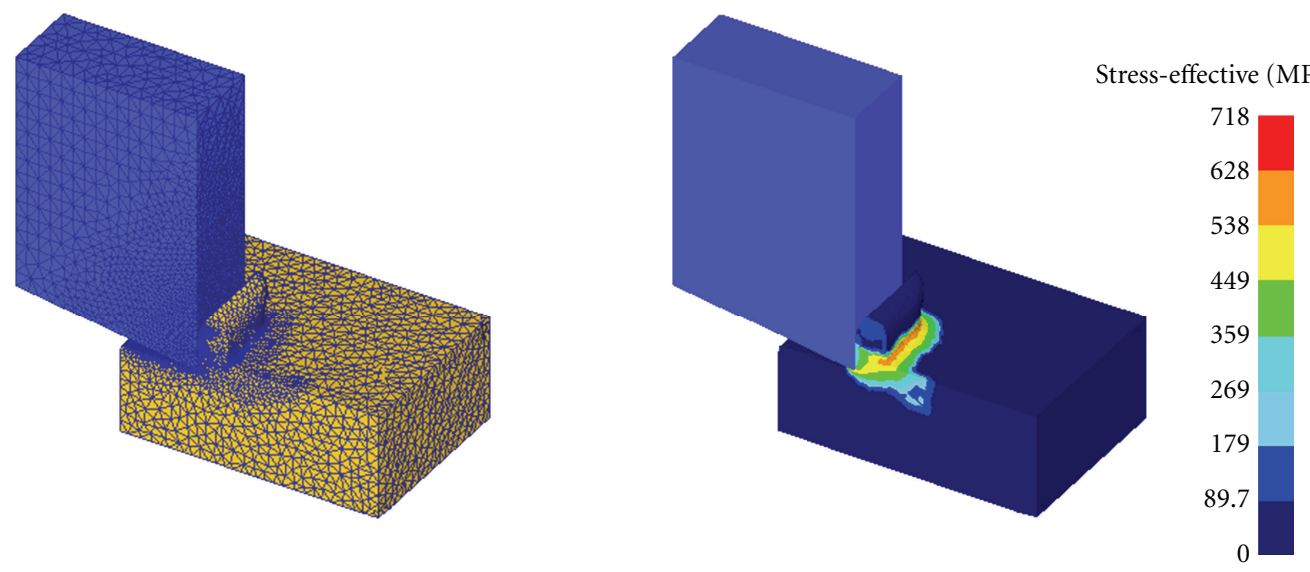

(b)

FIGURE 4: The history of the chip formation and the contour of effective stress.

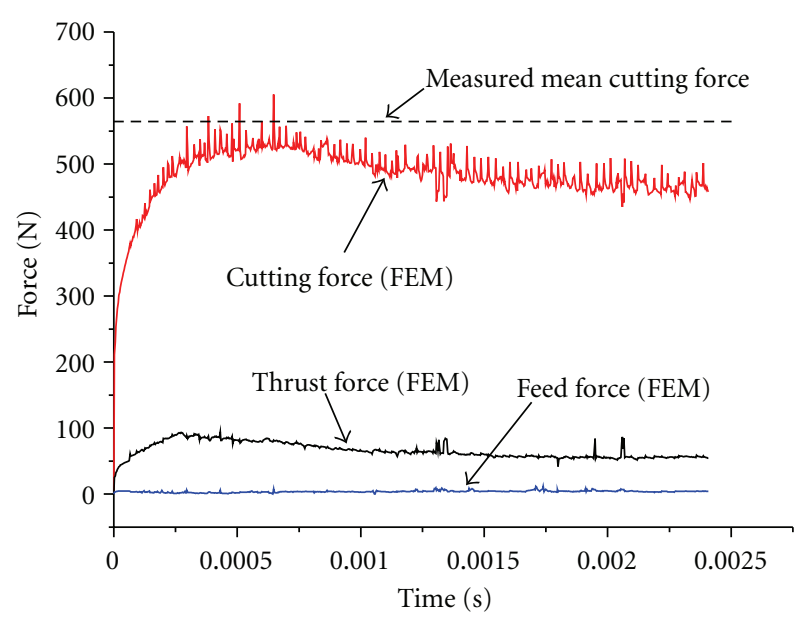

FIGURE 5: A comparison of simulated forces with experimental forces.

fraction of the undeformed layer, that is, material in the shear zone II, deviation from the direction of cutting velocity, and flow into the bulk top side and finally some of them turn into burr. Though the velocity is at very low level, most of outflow volume of the bulk may be harmful burr. Though the burr generation in conventional groove cutting cannot be avoided completely, optimized machining parameters may decrease the volume, that is, minimize the burr size.

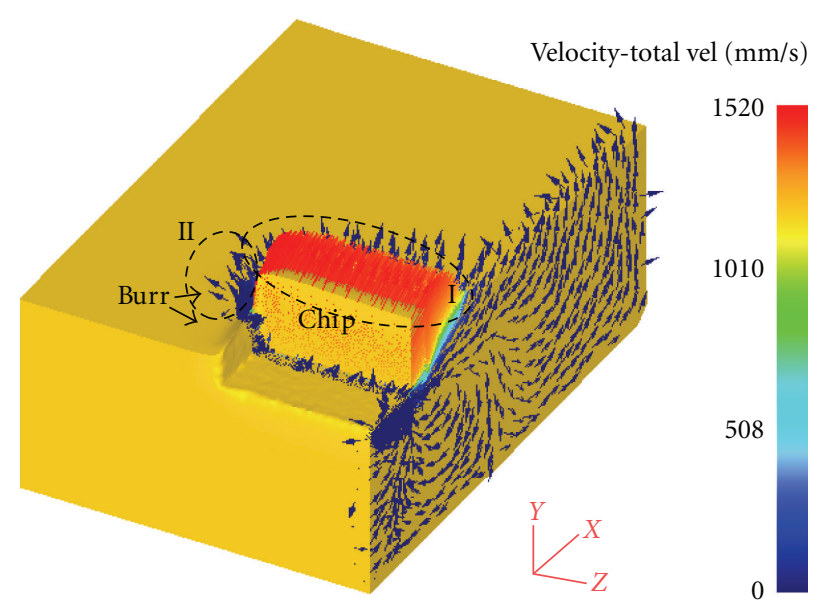

FIgURE 6: The material flow analysis during the cutting phase.

The burr profile in mesh style and cubic style is shown in Figure 7(a) after the cutting process gets to steady. It can be observed that the burr height and burr size increasing after the tool cut into the workpiece and then advances forward. The metallographic sample is also sectioned to the area of the steady burr formation by discharge machining. And then the experimental burr profile is copied from optical microscope images of the burr sample. Figure 7(b) shows the 

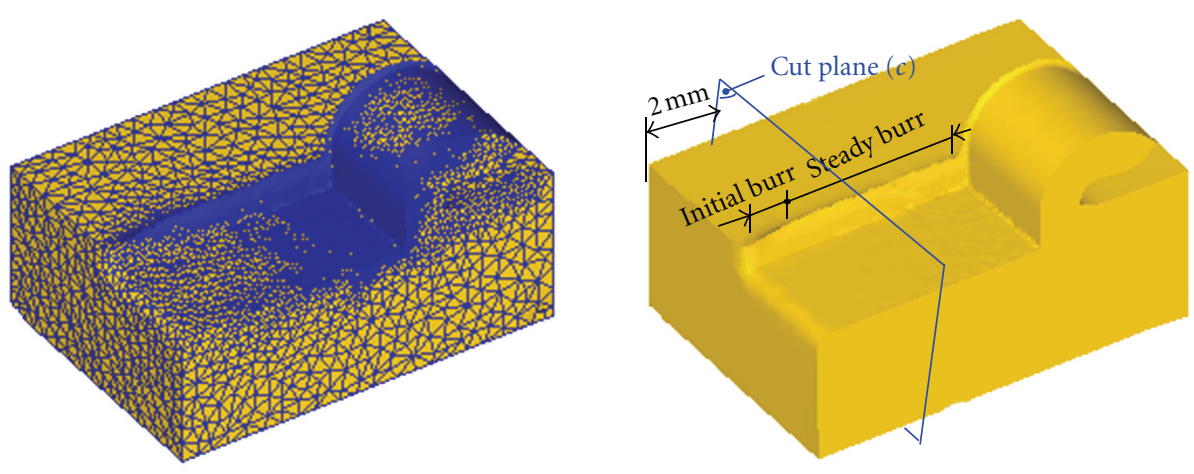

(a) The burr profile in mesh style and cubic style

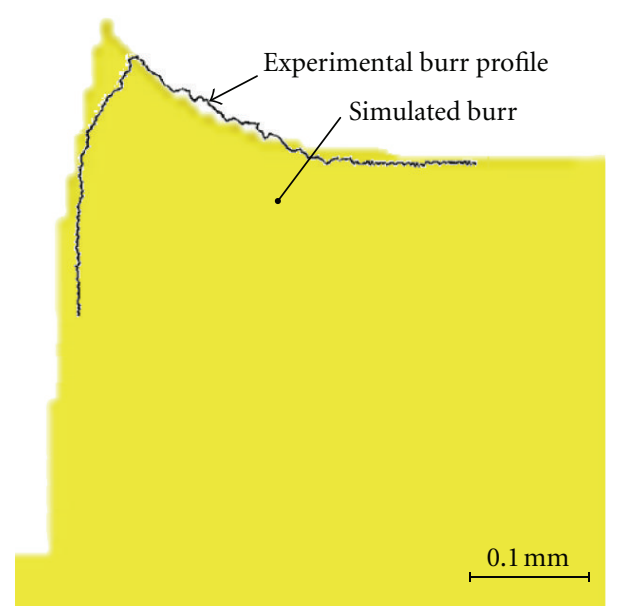

(b) The comparison of the simulated and experimental burr profile

FigURE 7: Burr formation at the top edge in rectangular groove cutting.

simulated and measured profiles of the steady burr. It seems that the established model simulate burr development with considerable accuracy.

3.2. Influence of Machining Parameters. Burr height was used as a burr size indicator in the present work as this was a relatively easy way of measurements. The height was measured as the average of 10 measurements for Burrs on top edge. Predicted burr profile is shown in Figure 8 for three different feed rates. It is quite obvious that the burr height at top edge increased steadily as the feed rate increases, while other machining parameters keep constant. The mean values of burr height are $0.07453,0.10812$, and $0.14074 \mathrm{~mm}$, respectively, at the feed rate of $0.1,0.2$, and $0.3 \mathrm{~mm}$. It can be concluded that the burr height is relatively larger for precision pats. It may introduce dimensional errors and cause of misfits in precision assembly. As mentioned previously, the Burr at the top side is formed by lateral deformation of the material when the cutting edge enters the workpiece. At low feed rate values, the volume of undeformed layer is small and can plastic flow more easily, therefore, relatively fewer of material flow into the bulk side and turned into burr. Whereas at high feed rate values the volume of undeformed layer is lager and plastic flow become difficulty. The material at the bilateral of undeformed layer is difficult to move forward and prior to move into the bulk side. Therefore, the volume of material that flows into the bulk side increased and the burr became larger.

Figure 9 shows the simulated burr profile under three different tool rake angle conditions. Regardless of the rake angle, the burr height keeps at a very low level during machining. The variation in rake angle significantly changes the magnitude of the burr height. The values of burr height are $0.14074,0.09353$, and $0.0786 \mathrm{~mm}$, respectively, at the rake angles of $0^{\circ}, 15^{\circ}$, and $30^{\circ}$. It is quite obvious that the maximum burr height at top edge decrease as the rake angle increases. Further, it is also noted that as the rake angle increases from $0^{\circ}$ to $15^{\circ}$, the maximum height decreases from 0.14074 to $0.09353 \mathrm{~mm}$, representing a reduction of around $0.05351 \mathrm{~mm}$. However, it was also found that when the rake angle increases from $15^{\circ}$ to $30^{\circ}$, the maximum value of burr height decreases from 0.09353 to $0.0786 \mathrm{~mm}$, a mere difference of $0.01493 \mathrm{~mm}$. This clearly indicates that the decrease of the burr height is quite limited when the rake angle increases from $15^{\circ}$ to $30^{\circ}$. However, as the rake angle decreases from $15^{\circ}$ to $0^{\circ}$, the increase of burr height goes beyond 50 percent from the previous amount.

In this study, the effect of cutting velocity and minor clearance angle on burr formation were also numerical studied. The minor clearance angle is illustrated in Figure 10 

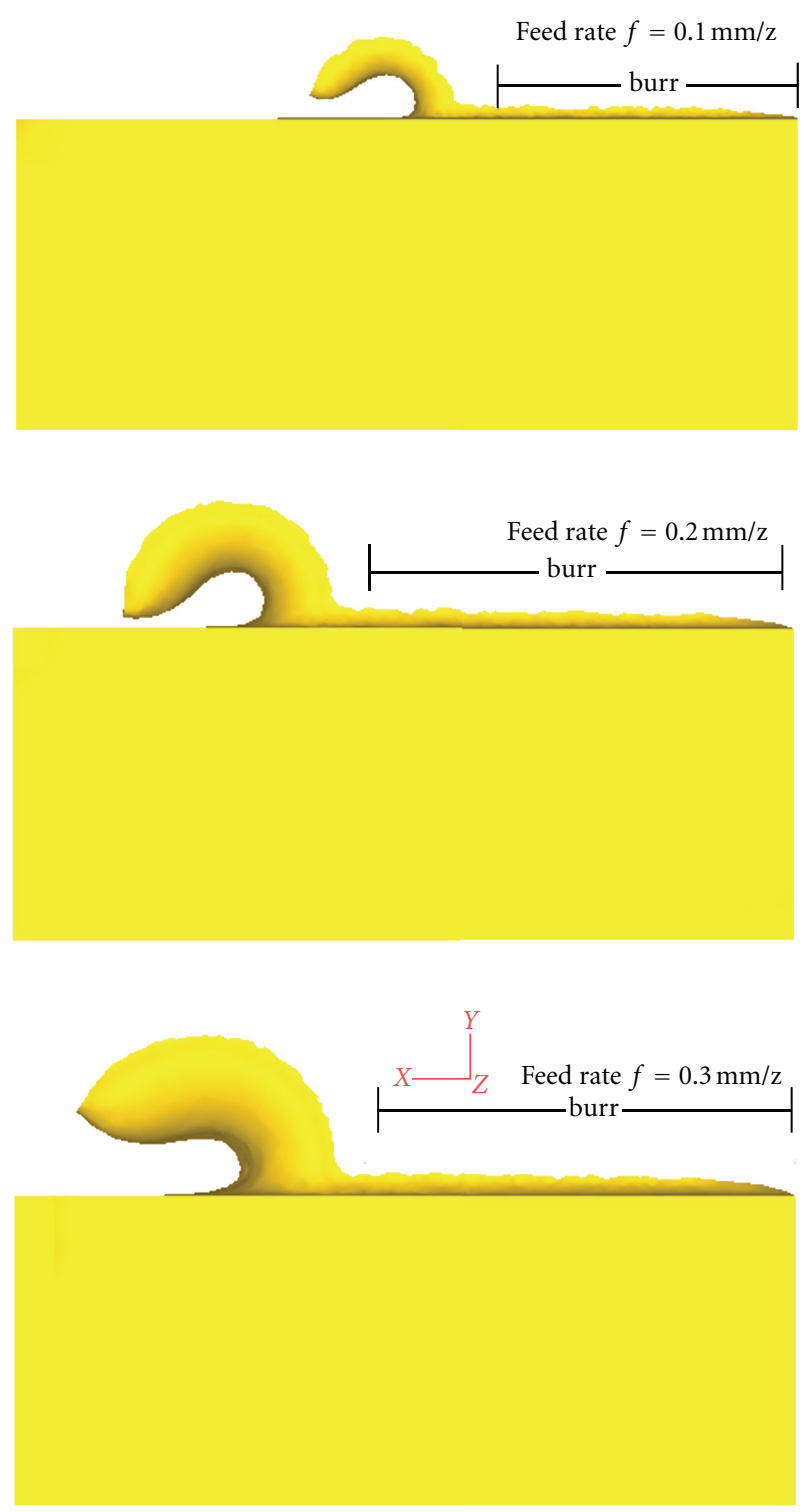

FIGURE 8: Burr profiles for different feed rate.

and is defined as the angle between the cutting velocity vector in orthogonal cutting and tool minor cutting edge plane. Comparison with the feed rate and rake angle, the effect of cutting velocity and minor clearance angle on the burr size are very slight. While the minor clearance angle increased increases from $0^{\circ}$ to $30^{\circ}$, the burr height decreases from 0.14074 to $0.13813 \mathrm{~mm}$, a mere difference of $0.00261 \mathrm{~mm}$. While cutting velocity increased from $0.5 \mathrm{~m} / \mathrm{s}$ to $2.5 \mathrm{~m} / \mathrm{s}$, the burr height decreases from 0.14074 to $0.13813 \mathrm{~mm}$, representing a mere difference of $0.00261 \mathrm{~mm}$. This clearly indicates that the effect of cutting velocity and minor clearance angle in the presented range on burr size are quite limited.

\section{Conclusions}

(1) A 3D finite element model to simulate rectangular groove cutting operation has been developed
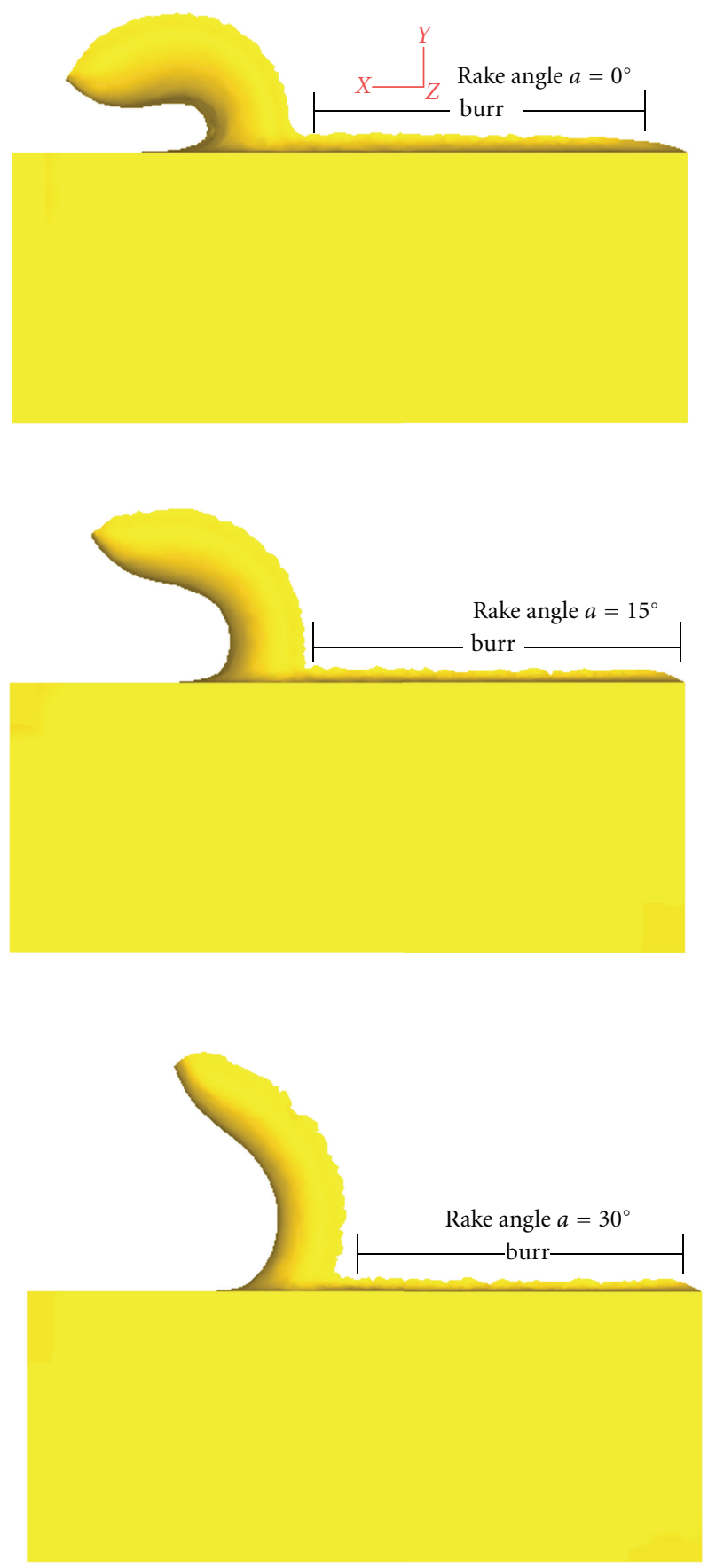

FIgURE 9: Burr profiles for different rake angle.

using commercial finite element software, employing experimentally determined mechanical properties at elevated strain rates and temperatures. The comparison of the simulated and experimental burr profile and cutting force proves that the developed model can capture the thermomechanical mechanisms in rectangular groove cutting and can simulate burr development with considerable accuracy.

(2) Parametric studies can be performed in order to understand the influence of different cutting parameters on the burr formation process in rectangular 


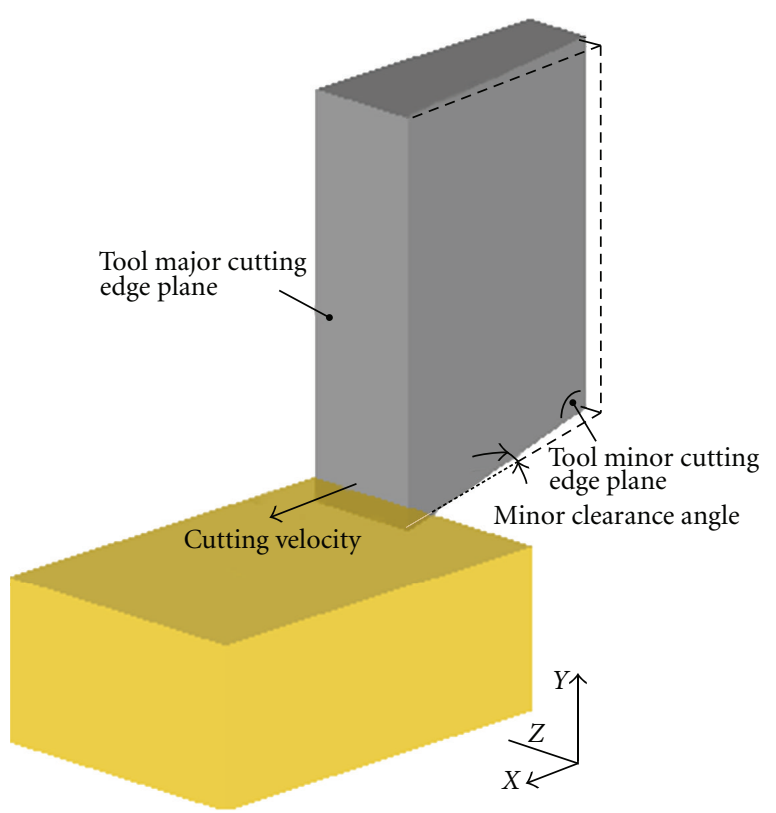

FIgure 10: The definition of minor clearance angle.

groove cutting operations. Although it is not possible to avoid burr formation by altering the cutting parameters, the burr size can be reduced significantly by selecting the appropriate values.

(3) The results show the burr height at top edge increased steadily as the feed rate increases. The mean values of burr height are $0.07453,0.10812$, and $0.14074 \mathrm{~mm}$, respectively, at the feed rate of $0.1,0.2$, and $0.3 \mathrm{~mm}$. For the larger feed rate values, the volume of undeformed layer is lager and plastic flow become difficulty. The material at the bilateral of undeformed layer is difficult to move forward and prior to move into the bulk side to form the burrs.

(4) The variation in rake angle significantly changes the magnitude of the burr height. The values of burr height are $0.14074,0.09353$, and $0.0786 \mathrm{~mm}$, respectively, at the rake angles of $0^{\circ}, 15^{\circ}$, and $30^{\circ}$. It is quite obvious that the maximum burr height at top edge decrease as the rake angle increases. The decrease of the burr height is quite limited when the rake angle increases from $15^{\circ}$ to $30^{\circ}$. However, as the rake angle decreases from $15^{\circ}$ to $0^{\circ}$, the increase of burr height goes beyond 50 percent from the previous amount.

(5) The effect of cutting velocity and minor clearance angle in the traditional range on burr size is quite limited.

(6) Computer modeling of burr formation, which belongs to the new concept of computational machining or virtual machining simulation, especially using a commercial FE code widely available to engineers and industry, constitutes a very useful tool for the prediction of the surface integrity of the workpiece as well as the optimum machining parameters, thus reducing the need for resorting to extensive cutting experiments.

\section{Acknowledgments}

This research was conducted under the support of the National Natural Science Foundation of China (50605022, 51075154), Fundamental Research Funds for the Central Universities (2012ZZ0057), Natural Science Foundation of Guangdong Province (06300160), and Zhujiang Science Technology New Stars Foundation (2011J2200066).

\section{References}

[1] L. K. Gillespie, The formation and properties of machining burrs, M.S. thesis, Utah State University, Logan, Utah, USA, 1973.

[2] L. K. Gillespie, "Burrs produced by end-milling," Bendix Report number BDX-613-1503, USA, 1976.

[3] K. Iwata, K. Ueda, and K., Ikuda, "Study of mechanism of bun-formation in cutting based on direct SEM observation," Journal of the Japan Society for Precision Engineering, vol. 48, no. 4, pp. 510-515, 1982.

[4] S. L. Ko and D. A. Dornfeld, "A study on burr formation mechanism," in Proceedings of the Symposium on Robotics, ASME DSC, ASME Winter Annual Meeting, vol. 11, p. 271, New York, NY, USA, 1988.

[5] S. L. Ko and D. A. Dornfeld, "Analysis and modelling of burr formation and breakout in metal," in Mechanics of Deburring and Surface Finishing Processes, R. J. Stango and P. R. Fitzpatrick, Eds., vol. PED 38, p. 79, ASME, New York, NY, USA, 1989.

[6] G. L. Chern, Analysis of buff formation and breakout in metal cutting, Ph.D. thesis, University of California, Berkeley, Calif, USA, 1993.

[7] Y. B. Guo and D. A. Dornfeld, "Finite element analysis of drilling burr minimization with a backup material," Journal of Engineering Materials and Technology, Transaction of ASME, vol. 122, pp. 207-211, 1998.

[8] I. W. Park and D. A. Dornfeld, "A study of burr formation processes using the finite element method: part II - The influences of exit angle, rake angle, and backup material on burr formation processes," Journal of Engineering Materials and Technology, Transaction of ASME, vol. 122, no. 2, pp. 221-228, 2000.

[9] I. W. Park and D. A. Dornfeld, "A study of burr formation processes using the finite element method: part II - The influences of exit angle, rake angle, and backup material on burr formation processes," Journal of Engineering Materials and Technology, Transactions of the ASME, vol. 122, no. 2, pp. 229237, 2000.

[10] S. Min, D. A. Dornfeld, J. Kim, and B. Shyu, "Finite element modeling of burr formation in metal cutting," Machining Science and Technology, vol. 5, no. 3, pp. 307-322, 2001.

[11] L. K. L. Saunders and C. A. Mauch, "An exit burr model for drilling of metals," Journal of Manufacturing Science and Engineering, Transactions of the ASME, vol. 123, no. 4, pp. 562$566,2001$.

[12] A. Toropov and S. L. Ko, "A model of burr formation in the feed direction in turning," International Journal of Machine Tools and Manufacture, vol. 46, no. 15, pp. 1913-1920, 2006. 
Advances in Materials Science and Engineering

9

[13] W. J. Deng, W. Kia, and Y. Tang, "Finite element simulation for burr formation near the exit of orthogonal cutting," International Journal of Advanced Manufacturing Technology, vol. 43, no. 9-10, pp. 1035-1045, 2009.

[14] P. Sartkulvanich, H. Sahlan, and T. Altan, "A finite element analysis of burr formation in face milling of a cast aluminum alloy," Machining Science and Technology, vol. 11, no. 2, pp. 157-181, 2007.

[15] X. Wang, H. Yon, C. Lang, B. Wu, H. X. Lu, and L. Cai, "Finite element modelling and analysis of cutting-direction burr formation," Key Engineering Materials, vol. 392-394, pp. 8892, 2009.

[16] L. Dong, L. Jianfeng, R. Yiming, S. Jie, Z. Jun, and Z. Wang, "A study of exit-burr formation mechanism using the finite element method in micro-cutting of aluminum alloy," Key Engineering Materials, vol. 375-376, pp. 470-473, 2008.

[17] B. Ackroyd, S. Chandrasekar, and W. D. Compton, "A model for the contact conditions at the chip-tool interface in machining," Journal of Tribology, vol. 125, no. 3, pp. 649-660, 2003.

[18] P. V. Asthakov, Tribology of Metal Cutting, vol. 52 of Tribology and Interface Engineering Series, 2006. 

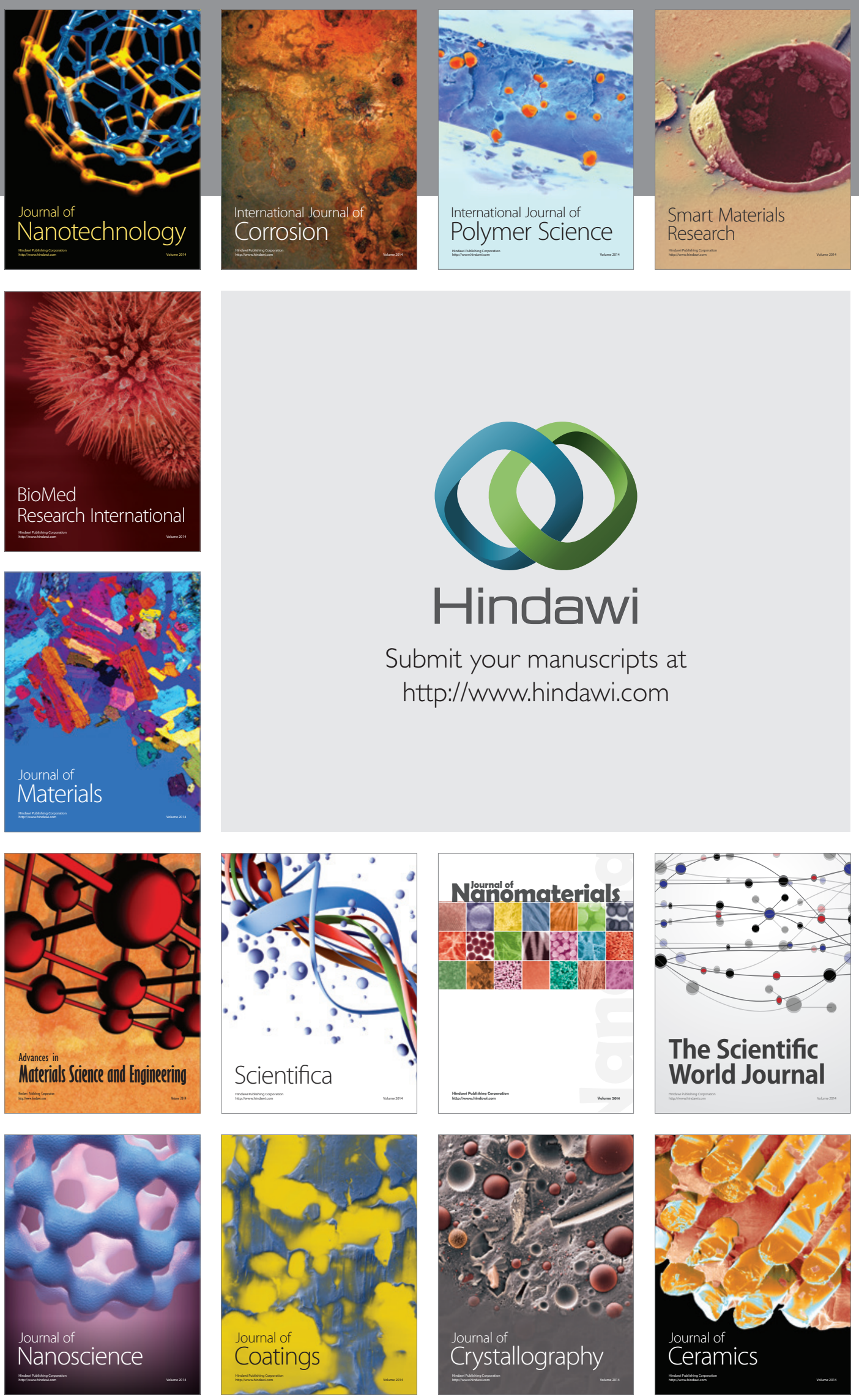

The Scientific World Journal

Submit your manuscripts at

http://www.hindawi.com

\section{World Journal}

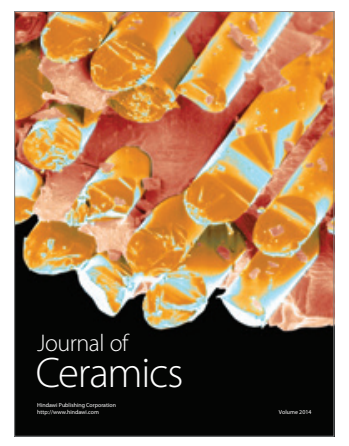

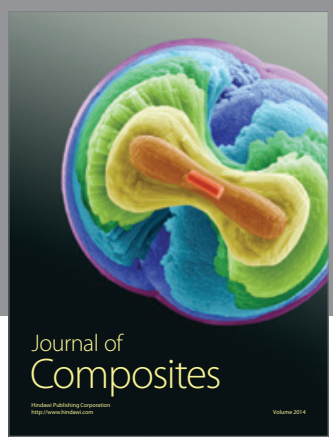
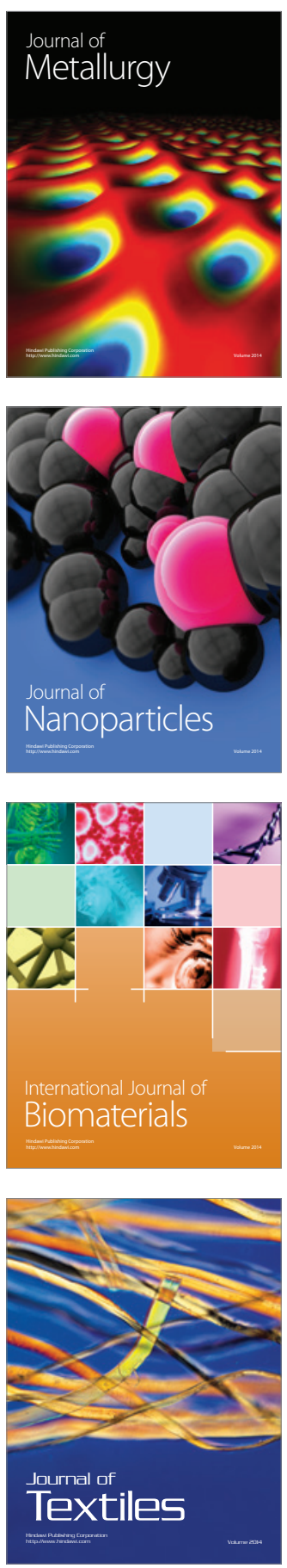